\title{
Living with faecal incontinence: trying to control the daily life that is out of control
}

\author{
Frida Olsson and Carina Berterö
}

\section{Linköping University Post Print}

\section{Tweet}

N.B.: When citing this work, cite the original article.

Original Publication:

Frida Olsson and Carina Berterö, Living with faecal incontinence: trying to control the daily life that is out of control, 2014, Journal of Clinical Nursing, (24), 141-150.

http://dx.doi.org/10.1111/jocn.12617

Copyright: Wiley: 12 months

http://eu.wiley.com/WileyCDA/

Postprint available at: Linköping University Electronic Press

http://urn.kb.se/resolve?urn=urn:nbn:se:liu:diva-113305 


\section{Living with faecal incontinence;}

\section{trying to control the daily life that is out of control}

Frida Olsson, MScN, Registered Nurse, Department of Surgery, Uppsala University Hospital, Uppsala Sweden

Carina Berterö, PhD, RNT, MScN, Professor, Division of Nursing, Department of Medical and Health Sciences, Faculty of Health Sciences, Linköping University, Linköping Sweden

Frida Olsson

Uppsala University Hospital

Department of Surgery

75185 Uppsala

Sweden

Telephone: +46186114514

E-mail: frida.olsson@akademiska.se

Professor Carina Berterö

Division of Nursing, Department of Medical and Health Sciences,

Faculty of Health Sciences, Linköping University

58183 Linköping

Sweden

Telephone: +46 13-286974

E- mail: carina.bertero@liu.se 


\section{Abstract}

Aims and objectives. To identify and describe the lived experience of persons living with faecal incontinence and show how it affects daily life.

Background. Faecal incontinence is a relatively common condition, with a prevalence ranging from $3-24 \%$, not differing between men and women. There is an under-reporting due to patients' reluctance to talk about their symptoms and consult health care professionals about their problems, which means that problems related to faecal incontinence are often underestimated. Living with faecal incontinence affects the quality of life negatively and has a negative impact on family situations, social interaction etc.

Design. A qualitative interpretative study based on interviews.

Methods. In-depth interviews were conducted with five informants, all women, living with faecal incontinence. The interviews were transcribed verbatim and analysed using interpretive phenomenological analysis (IPA).

Results. The analysis identified four themes: self-affirmation, guilt and shame, limitations in life, and personal approach. The themes differ from each other but are related and have similarities. The results show different aspects of living with faecal incontinence and how they affected daily life.

Conclusions. Living with faecal incontinence is a complex problem affecting everyday life in a number of different ways. It is a highly distressing and socially incapacitating problem. Living with faecal incontinence is about trying to control the daily life which is out of control. Living with faecal incontinence cannot be generalized since individuals experience the situation in unique ways.

Relevance to clinical practice. By gaining insight into the experience of living with faecal incontinence health care professionals can deepen their understanding of this complex 
problem and thereby address it better and provide more individually-based care.

Keywords: faecal incontinence, patient experiences, impact on daily life, interpretative phenomenology, self-affirmation, personal approach, life limitations, guilt and shame

\section{What does this paper contribute to the wider global clinical community?}

- Little is known about the individual experience of living with faecal incontinence and its complex problems. This study provides an insight into how it is to live with faecal incontinence and its impact on daily life. To our knowledge we have identified two themes not found in other research in this area; self-affirmation and personal approach.

- Most individuals living with faecal incontinence are not willing to talk about their problems due to embarrassment. If the issues concerning the condition are given more attention and the related problems due to faecal incontinence are presented, perhaps those who previously have not sought help for their symptoms and problems will decide to do so.

- There is a lack of public information about faecal incontinence. It is important to address all problems related to faecal incontinence since health care services have a responsibility to alert and inform about the condition. In order to help persons with FI health care providers also have a responsibility to ask confirmatory routine questions about FI. 


\section{Introduction}

Evidence shows that faecal incontinence (FI) is a relatively common issue, which causes suffering among individuals with significant physiological, psychological and social consequences. Symptoms are often underestimated and the condition is not sufficiently addressed. Few of those living with FI chooses to seek treatment for their symptoms. Living with FI causes individual suffering and reduced quality of life (QOL) and can have a major negative impact on daily life.

\section{Background}

There are several definitions of FI. The most common definition is involuntary loss of flatus, soiling, liquid and/or solid stool, as single sole symptoms or in combination (Barlett \& Ho 2009, Whitehead et al. 2009, Ratto et al. 2011). However, involuntary passage of flatus should probably not be characterized as FI because it is difficult to define when the involuntary passage of flatus is abnormal (Bharucha 2003). Incontinence may be passive or urge. Passive incontinence is when the patient is unaware of the faecal loss, and urge is where the patient leaks stool while trying to reach the toilet. Passive and urge incontinence can occur together in the same patient. FI is also defined by severity, i.e. the frequency of incontinence, which can range from rare occasions yearly or monthly to an everyday event (Bartlett \& Ho 2009).

The prevalence of FI is difficult to estimate. Partly because there is an under-reporting due to patients' reluctance to talk about their symptoms or consult health care professionals about their problems (Walter et al. 2002, Nelson 2004, Bharucha et al. 2005). This in turn leads to the problem often being underestimated (Nelson 2004, Bharucha et al. 2005). It has been shown that women are more willing to report symptoms of FI than men (Nelson 2004). The 
prevalence of FI ranges in studies from $3-24 \%$ and does not differ between men and women (Perry et al. 2002, Walter et al. 2002, Bharucha et al. 2005, Melville et al. 2005, Whitehead et $a l, 2009$ ). However, the prevalence increases steadily with age (Perry et al. 2002, Lunniss et al. 2004, Nelson 2004, Melville et al. 2005, Bharucha et al. 2006). Different prevalence rates presented in studies are probably also reflected by varying definitions of FI (Nelson 2004, Bharucha et al. 2005) and how the severity of FI is defined (Perry et al. 2002, Whitehead et al. 2009).

There are several possible causes of FI (Lunniss et al. 2004, Nelson 2004). Most individuals become faecally incontinent as a result of some form of insult such as obstetric trauma or pelvic surgery (Lunniss et al. 2004). For many individuals, FI is the result of a combination of structural such as internal or external sphincter injury, physiological and psycho-social factors (Norton 2004, Tuteja \& Rao 2004). The most commonly reported risk factor for FI in women is damage to the pudenda nerve or sphincter muscle from prior obstetric trauma (Lunniss et al. 2004, Nelson 2004). In men, anal surgery is the most commonly reported risk factor, with haemorrhoidectomy the most frequent procedure reported. In some cases, the cause-effect relation is known, and the pathophysiology may be demonstrable by anorectal function testing. However, symptoms may not develop until many years after the event and the relation between cause and effect may then be unclear (Lunniss et al. 2004).

Several diseases are associated with FI, such as diabetes, multiple sclerosis, Inflammatory Bowel Disease (IBD) and Parkinson's disease (Nelson 2004). Even neurological damage of the pelvic floor muscles from spinal cord injury, or damage to the sacral nerve roots and radiation to the pelvis can cause FI (Bharucha 2003, Philip \& Miner 2004). Often, FI is a combination of several factors, along with reduced pelvic floor muscles (Bharucha 2003). 
A number of treatment options are available for FI. These range from conservative measures aimed at symptom control to interventions, non-operative and operative techniques, aimed at correcting the underlying cause (Tuteja \& Rao 2004). The method used to treat the incontinence depends on the underlying disorder and the impact on QOL (Madoff 2004). Modifying bowel habits using antidiarrheal drugs is often the cornerstone to effectively managing incontinence (Bharucha 2003). Other treatment options are intestine treatment as Biofeedback (Norton et al. 2005a), anal plug (Tuteja \& Rao 2004), operative techniques such as levatorplasty, sphincteroplasty (Brown et al. 2013) gracioloplasty (Tan et al. 2007) and minimally invasive approaches such as sacral nerve stimulation (Mowatt et al. 2009). FI can also be treated with injectable bulking agents (Stojkovic et al. 2006, Danielson et al. 2009, Ratto et al. 2011) or formation of a stoma ( Norton et al. 2005b).

Living with FI often affects the QOL negatively (Bharucha et al. 2005, Smith et al. 2013). Anxiety, low self-esteem and depression are strongly associated with FI (Bharucha 2003, Lo et al. 2010). Family situations, working conditions, social interaction and sexual life are affected negatively (Bharucha et al. 2005). Those living with FI have a constant fear and anxiety about the risk of leaking in public and embarrassment leading to negative impact on social interaction which in turn leads to isolation. Their home becomes their comfort zone and to deal with the situation ones uses different types of behaviour routines (Peden-McAlpine et al. 2008, Peden-McAlpine et al. 2012). A similar negative impact on QOL can be seen among those living with a stoma which is strongly associated with taboo, guilt and shame, limitations in daily life and negative effects on social interaction and work conditions (Danielsen et al. 2013).

There is a lack of knowledge about their experiences of living with FI and how it affects daily life as few studies relates to persons living with FI and their perspectives. This study aims to 
identify and describe the lived experience of persons living with FI and show how it affects daily life.

\section{Method}

\section{Design}

To achieve a good understanding of people living with FI a qualitative approach with interpretive phenomenology was considered most appropriate. In this study, Interpretative Phenomenological Analysis (IPA) was used.

IPA focuses upon people's understanding of the lived experiences, the everyday life and their relationship to the phenomena. IPA aims to offer the perspective of those who experience the phenomena, while the researcher uses his own pre-understanding in order to understand and interpret their world and explain their daily life. The aim is not to generalize but to say something in detail about a specific group experience (Smith \& Osborn 2008, Smith et al. 2009). One of the authors, F.O, is working with this patient group and therefor has some preunderstanding for the phenomena.

\section{Participants}

In this study, FI is defined as involuntary loss of flatus, soiling, liquid and/or solid stool, as single sole symptoms or in combination.

When using IPA the samples are selected purposively and as homogeneously as possible. Participants are selected on the basis that they can report information about the particular perspective under study (Smith et al. 2009).

The inclusion criteria for this study were adults, over 18 years of age, with FI regardless of the cause or severity, and experience of symptoms. Informants had to be able to manage to take 
care of activities of daily living (ADL). Informants were excluded if not able to speak or write in Swedish, if they were living in a nursing home or other type of health care facility, or if living at home with great nursing needs from home care, relatives or other persons with regard to ADL. Persons with the single symptom of involuntary loss of flatus were excluded. Informants who F.O herself had cared for were also excluded.

The informants were recruited through the department of colorectal surgery at a large university hospital in Sweden. The informants were identified by the coordinator of colorectal surgery from those waiting for a planned surgical approach for FI. Informants were also recruited through the outpatient clinic, of the same hospital, by two intestine therapists from those undergoing treatment or those waiting for treatment for FI. The coordinator and the intestine therapists were asked to recruit informants who met the inclusion criteria.

A letter with information about the study and an invitation to participate in the study was sent out to the informants from the coordinator for colorectal surgery and intestine therapists. Those who wanted to participate in the study responded via letter to F.O and gave informed consent. F.O contacted those who had given their informed consent by telephone or email and arrangements were made for the interviews.

A total of 15 women and five men, between 31-79 years of age, were invited to participate in the study. A test interview was conducted with those who were invited to participate. This interview was considered to be of such quality that it was included in the study. A total of five informants, the test interview included, all women aged 31 to 75 (median 45 years), agreed to participate in the study. Since the primary concern of IPA is detailed interpretation of individual experiences, IPA studies usually benefit from a small number of cases (Smith \& Osborn 2008, Smith et al. 2009). Between three and six participants is a reasonable sample size (Smith et al. 2009). 


\section{Data collection}

Data were collected using qualitative in-depth interviews. The interviews were recorded and were of the individual, face-to-face type. An interview guide was used to ensure that the interviews focused on the purpose of the study. The interview guide was designed according to Kvale (1996) and Smith and Osborn (2008).

The interview guide consisted of two open-ended questions to get the informants to describe the most important dimensions of the phenomenon. The interviews began with the request: "Tell me how it is to live with FI" and followed by "Tell me as detailed as possible how living with FI affects your daily life". Probing questions like requests about telling more about an incident or similar were used continuously during the interviews to increase the depth and richness of the informants' stories. The informants were asked to talk as widely as possible about their experiences of living with FI.

Qualitative interviews were conducted by F.O. during April to September 2013. The interviews were carried out in locations selected by the informants: Two in informants' homes and three in a secluded location at the hospital. The interviews lasted from 43 to 88 minutes (median 65 minutes). All interviews were transcribed verbatim by F.O shortly after they were conducted.

\section{Analysis}

The transcribed interviews were the data used for the analysis, which was conducted using the IPA methods described by Smith, Flowers and Larkin (2009). The analysis was made by F.O. In order to increase the validity of the findings, the analysis was subjected to peer-debriefing and was continuously scrutinized by an additional researcher, C.B. Analysis was performed rigorously, using the six steps of the analytic process. Each interview was analysed separately. The first step of the analysis was to read each transcribed interview several times to become 
familiar with the text and to get an overall impression. After reading the transcripts, several times the interviews was analysed and interpreted using initial noting. Notes were made about aspects of the interviews related to the aim of the study. Based on the initial notes different themes were developed. As each transcript was analysed, several prominent themes emerged and connections between these themes were sought separately for each interview. Prominent themes were then grouped together from all the interviews and similar themes were combined. Finally, four themes remained. The final step was to interpret and explain the themes and to show similarities, variations and unique experiences (Smith et al. 2009).

When assessing validity in IPA it is important to consider: sensitivity to context, commitment and rigour, transparency and coherence, impact and importance. What actually was been said by the participants. Verbatim quotations are included to provide means of validation (Smith et al. 2009).

\section{Ethical approval}

All informants received both oral and written information about the study and gave their informed consent to participate. They were also assured that they could leave the study at any time. Information was given that the interview material would be treated with secrecy and would remain confidential at all times. Permission to carry out the study was received from the head of the clinical department. The study was performed in accordance with the Declaration of Helsinki and Swedish legislation of non-invasive studies (Swedish Code of Statutes 2003/2008, World Medical Association 2008). According to Swedish law, ethical approval is not required for research studies conducted during advanced educational programmes, but all considerations was given to ethical laws and guidelines. 


\section{Result}

The analysis resulted in four different themes: self-affirmation, guilt and shame, limitations in life, and personal approach. The themes differed but were related to each other, had similarities and showed different aspects of the phenomena. The results are described in the text and illustrated with quotations from the informants.

\section{Self-affirmation}

Some of the informants expressed preconceptions that others would perceive them negatively if they found out they suffered from FI. They have already decided that others perceive them as repulsive and impolite, although they do not know for sure if that is the case. This in turn affects their self-perception and self-esteem negatively. Some, on the other hand, said that they no longer care what people think of them, or at least in the future they would hopefully stop worrying about what others think of them.

It is important for the informants to gain understanding from those close to them and that these people show consideration. But, sometimes the informants had not been clear about the issue and then it is hard to expect understanding from those closest to them.

The informants expressed the importance of a positive approach in contact with physicians, i.e. being treated with empathy, having their problems taken seriously, and being listened to. They also stressed the importance of being seen as an individual. Some of the informants had experienced that physicians had not listened to what they wanted to say, and their problems 
were generalized. Physicians acted on the basis that they were working with these problems every day and therefore were familiar with the subject, while the informants felt that they were not given the opportunity to present the issue from their own perspective. In relation to others, some informants expressed not being valued. Informants felt that physicians do not have any sympathy and didn't feel involved in decisions including further investigation or treatments:

They just told me that there's nothing they can do, without any explanation.

Am I too old? Do they think it is meaningless? (I 4, raw, 22-23).

However, others stated that they received good treatment from health care services and had a positive experience.

The informants stated that they participated in the study because they wanted to share their experiences. They want the problem to be addressed and help others in the same situation; so that others dare to talk about it and seek help from health care. They feel there is a lack of information about FI in society and it is important that the problem be addressed. Health care services, and especially maternity care services, have a responsibility to alert and inform about FI.

\section{Guilt and shame}

During the interviews, the informants sometimes had difficulty putting their experiences into words, especially when talking about relationships to partners and friends, sexuality and negative experiences associated in contact with health care. It is a sensitive topic to talk about and strongly associated with emotions such as guilt and shame. The informants described FI as a subject associated with taboo even though this was not the specific word they used. It is embarrassing to live with FI, and there are feelings of guilt. Much revolves around anxiety and fear of leakage in public, smelling bad, and what others will think of them. 
If it happens ... when you're with someone else. I feel ashamed.

I embarrassed a lot. God, what will they think about me? What will

others think? (I5 raw 437-438).

There are negative feelings associated with living with FI, such as anger, frustration, injustice, disappointment, hopelessness, despair and sadness. Living with FI is the worst thing to suffer. It was expressed as: It's a living hell (I 2, raw, 57). It is insanitary, smells bad, and sounds bad when going to the toilet. FI is disgusting and repugnant: it is shameful. Not attending social events due to shame is common and the informants said that they pretended to have headaches or stomach problems, instead of telling the real reason.

There were ambivalent expressions about this issue; the informants stated that they could talk about it and it was important to talk about it. But, later on they said that they choose not to tell people in their social circle. The subject is too private and embarrassing to talk about.

However, all of them have told their partner. In addition to their partners they have talked to health care professionals, but have told few others about their problems.

Guilt and shame were also related to health care. Some stated that they felt neglected, vulnerable and questioned in contact with physicians. The humiliating diagnostic exams as part of the investigation for FI were portrayed as repulsive.

Living with FI is not a condition that is visible (unless there is leakage); the appeal is not noticeable to others. Some informants said that it would have been easier if their problems are recognizable. On the other hand, trying to hide it is of critical importance.

\section{Limitations in life}

The informants said that their lives had changed and are limited in one way or another; for some radical. 
Everyday life involves practical, often time-consuming strategies to try to control the situation and avoid leakage. One's plan defecating by: going to the toilet frequently, going to the toilet right after meals, avoiding certain kinds of food, and taking enemas in the morning. The smell is a problem related to leakage and the informants has strategies for that as well; avoiding going to the toilets when not at home and constantly managing genital hygiene. The informants use various types of protection against leakage such as diapers or pant liners. Some of them experiences constant leakage while others has occasional leakage. Once they leave home, they always have to carry diapers, extra clothes etc. in case of leakage. Some of the informants decide to stay at home due to all this extra work.

Some are trying to manage the situation by establishing daily routines. For some it is impossible to plan the day and take it as it come. Others have to prepare and plan for everything and are rarely able to do something spontaneous. One even has to plan for having sex. Even with strategies to avoid leakage and unexpected events, there is never any guarantee that there would be no leak. One could never feel safe and it is always in your thoughts. Ones live in a fragile existence where life more or less revolved around living with FI:

You always think of that something might happen (laughs) ...

So there is always a slight of psychological pressure (I 1, row, 63-65).

Living with FI affects the relationship and closeness with their partner. Some of the informants avoid sex due to fear of leakage during intercourse while some said that it do not affect their sex life. One informant decided to stay single for the rest of her life:

When I got this I decided that I should live as a single person for the rest of my life. I was single at the time. I thought that I could not go out and meet a partner. How would this be done? I mean I constantly have stool 
in my pants. It's impossible. And what about the sexual part, I do not know

if I will leak or not. It was terrible (I 2, row, 19-24).

For some, home became their comfort zone where they do not need to worry about leakage and unpleasant situations in front of others. Therefore, they avoid social interaction. It is easier to deal with the situation at home, and in consequence, some of the informants isolate themselves. Some however said that their problem is not affecting social interaction and they spend time with family and friends and engaged in activities to the same extent as before.

When away from home, the informants have to know where the toilet is and constantly stay close to a toilet to feel reasonably comfortable and secure. This is partly to try to get there in time but also to verify possible leakage and to take care of hygiene.

Some of the working-age informants said that they could not work full time or at all, or not to the extent desired. Life is also limited by avoiding going on vacation, to bath or sunbathing in public places, foreign travel or long trips. Some cannot travel on public transportation, and thus are dependent on a car. Some avoids physical activity.

The leakages also invariably leads to other problems such as constantly getting urinary tract infections, a burning pain in the genitals, or having permanently sore skin.

\section{Personal approach}

FI is a complex problem. The informants relates to their incontinence in various ways. It is difficult, and for some impossible, to accept the situation they live in. Some of them said that in order to deal with the situation they have to adapt to it. It is difficult to live with FI but life has to go on anyway.

The informants always expect the worst case scenario. When having leakage in public they pretend that nothing has happened and seeks to repress the hardest situations. Some tries to 
handle everyday events by joking about them, laugh at the misery, and feeling sorry for themselves for a while. Others try to expose themselves to unusual situations and do things they do not really believe manageable or comfortable.

Their personal approach is also related to how they see themselves in relation to others. There are those who have it worse than me. It is not a fatal disease. Others may also come to suffer from it. They have to be hopeful and optimistic that life would get better. At the same time, there is a concern that it would get worse in the future, with aging, and they would become dependent on others. It is also linked to self- perception:

I think it's hard to live with it .... It reflects a lot of my self-image .... How I perceive myself physically. I have other images of how I see myself as a human and I am competent in other ways, but as a woman ... As a physical object, I feel ... devastated ...(I3, raw, 388-392).

If the informants have to talk about their incontinence they can only do so if they feel comfortable and confident with those they speak to. The informants stated that they could talk about their problems with others if those others began the discussion. It is easier telling them they feel a kind of affinity with such other women in a maternity group. Some said they could talk about it with close friends and family.

The informants had themselves sought care and had several health care contacts related to their FI. By asking for help you also show that you care about your health. They all have confidence in and expectations of being able to get help from the health care services. Those who have not been able to get the help they expected feel great disappointment:

It's a problem that I have no part in ... as I myself have not been able to influence it. I think more that it is the hospital's fault because 
of the surgery (refers to vaginal operation) which has caused things

to become like this (I 4, raw, 181-184).

Those without an explanation for the cause said that it was important for them to find an explanation. They feel that it would be easier to accept the situation if they have an explanation for their symptoms. They with coexisting urinary incontinence said that it is easier to live with than faecal incontinence.

\section{Discussion}

To our knowledge, there is little known about the experience of living with FI. Our results show that living with FI has a major impact and its effects extend into all dimensions of daily life.

There are a number of studies showing that living with FI affects QOL negatively (Bharucha 2003, Bharucha et al. 2005, Bordeianou et al. 2007, Bartlett et al. 2009, Lo et al. 2010, Danielson et al. 2013) which coincide with our results. Our study results have similarities with the results presented in the phenomenological studies by Peden-McAlpine et al., regarding the constant fear and anxiety about the risk of leaking in public and negative impact on social interaction (Peden-McAlpine et al. 2008, Peden-McAlpine et al. 2012).

Our study shows that living with FI has a lot in common with living with a stoma. Like FI living with a stoma is associated with taboo, guilt and shame and a persistent need for control (Danielsen et al. 2013). It also limits the daily life due to concerns about the smell of the bag etc. (Manderson 2005, Andersson et al. 2010) and social burden leading to isolation and effecting sexual life negatively (Manderson 2005).

To our knowledge we have identified two themes not found in other research in this area; selfaffirmation and personal approach. Why these two themes are not described in previous 
studies may be due to those unique informants participating in our study. Individuals perceive their experiences of living with FI in different ways. The informants in our study described themselves to a large extent based on how others may perceive them and how they relate to their FI etc. This is not described in previous studies where participants focus on how to resolve their situation practically.

Those are, however, described in relation to medical conditions in other patient populations. In a study including cancer patients, informants described being listened to and feeling seen as an individual in relation to health care providers of great importance. They also described that they were trying to have optimistic thoughts and using humor to gain control over the situation (Rotegård et al. 2012). This is consistent with the result in our study.

How others perceived the informants was a constantly recurring subject during the interviews in our study. In a study by Cooper et al. (2010) with IBD patients, informants talked about self-perception and how they feel other perceive them negatively. They also described how they are trying to adapt to a situation difficult to accept. This is similar to our results.

A limitation of our study is that only women agreed to participate. There were few men available to ask about participation and none of the invited men wanted to participate in the study. One can only speculate about whether the result would have been different if some men had participated in the study. Women are used to handle menstrual bleeding and therefor odor and practical matters related to menstruation (Brantelid et al. 2013). Therefore it is possible that women relates to FI in a different way since they are used to using pads and dealing with their genital area.

One may wonder whether men and women deal with medical conditions in different ways and if there are gender differences with regard to how it affects QOL? In a study on patients with heart failure the results indicates that there are no gender differences in physical and 
emotional symptom status or health-related QOL (Heo et al. 2007). On the other hand, in another study including heart failure patients, women showed more symptoms of depression then men (Eastwood et al. 2012). In a study measuring QOL in oncology patients with cancer pain result showed that QOL were significantly lower among women than men (Pud 2011).

With regard to the above, is it possible that women living with FI relates to their situation differently and have worse QOL than men? The aim of our study was not to compare the experience of living with FI between genders. It would, however, be interesting to do a study with the same aim with only men included. It would also be interesting to conduct a study with the same purpose among those who does not have sought health care for their symptoms. Do they relate to their FI in some other way?

The informants who participated in the study described many similar experiences which may be due to a homogenous group with similar experiences. It is possible and even likely that more informants or other informants would have described the situation in another way. At the same time the aim of IPA is to say something about a specific group and the result of our study cannot be used to generalize for all those living with FI. The results of our study may have been affected by the fact that some of the informants were waiting for planned surgery while some were undergoing treatment or waiting for treatment for their FI. It is possible that the result would have been different if those undergoing treatment for their FI had not participated in the study. This could only be speculated on. On the other hand, we believe that the living with FI was the important factor, generating experiences presented.

The validity of the study has been secured since sensitivity to context, commitment and rigour, transparency and coherence and impact and importance, described by Smith et al. 2009, has been taken into account throughout the whole research process. To ensure validity verbatim quotations also has been used (Smith et al. 2009). Given the aim of the study the 
authors consider that it was entitled to use IPA as a research method. Alternative method could have been critical incident. Given what the informants talked about during the interviews it would have been interesting to do a study using this method. Considering that it was difficult to recruit informants to the study and it requires far more participants to conduct a study with critical incident as a method, it may be difficult to conduct.

\section{Conclusion}

Living with FI is a complex problem were one are trying to control the daily life which is out of control. Our study has identified different issues which illuminate the lived experience of FI including self-affirmation, guilt and shame, limitations in life, and personal approach. There are some common patterns applicable to living with FI, especially with regard to how others perceive the sufferer. However, there is also a variety of ways in which everyday life is affected and living with FI cannot be generalized since individuals experience the situation in unique ways.

\section{Relevance to clinical practice}

By gaining insight into the experience of living with FI, health care professionals can deepen their understanding of this complex problem and thereby address issues better and provide more individually-based care. The informants in our study ask for a more positive approach in contact with health care and especially with physicians. It is of great importance to be treated with empathy, having the problems related to FI taken seriously and above all of being seen as an individual and being listened to. It is important that health gives attention to this and is responsive to what the patients has to say. It is also very important that healthcare professionals affect the themes that are described in the result of this study. Even if the patient does not himself initiate to talk about guilt and shame, or how life is affected etc. health care professionals should initiate these issues. 
The informants in the study stated that they participated in the study because they wanted to share their experiences, to address the problem and help others in the same situation. Health care services therefore have the responsibility to alert and inform the public about FI. If the issue is given more attention and are presented, maybe those who previously have not have sought help for their symptoms and related problems will decide to do so. In order to help persons with FI health care providers have a responsibility to ask confirmatory routine questions about FI.

\section{Acknowledgements}

We are grateful to all patients who participated in our study and shared their experiences with us. We are also grateful to the coordinator of colorectal surgery and the intestine-therapists who recruited patients to our study.

\section{Contributors}

Study design FO, CB; data collection and analysis: FO, CB; and manuscript preparation FO, CB.

\section{Conflict of interest}

All authors declare no conflict of interest. 


\section{References}

Andersson G, Engström Å \& Söderberg S (2010) A chance to live: Women's experiences of living with a colostomy after rectal cancer surgery. International Journal of Nursing Practice 16, 603-608.

Bartlett L \& Ho Y-H (2009) PTQ anal implants for the treatment of faecal incontinence. British Journal of Surgery 96, 1468-1475.

Bartlett L, Nowak M \& Ho Y-H (2009) Impact of fecal incontinence on quality of life. World Journal of Gastroenterology 26, 3276-3282.

Bharucha A (2003) Fecal Incontinence. Gastroenterology 124, 1672-1685.

Bharucha A, Zinsmeister A, Locke R, Seide B, Mckeon K, Schleck C \& Melton J (2005) Prevalence and Burden of Fecal Incontinence: A Population-Based Study in Women. Gastroenterology 129, 42-49.

Bharucha A, Zinsmeister A, Locke R, Seide B, McKeon K, Schleck C \& Melton J (2006) Risk Factors for Fecal Incontinence: A Population-based Study in Women. American Journal of Gastroenterology 101, 1305-1312.

Bordeianou L, Rockwood T, Baxter N, Lowry A, Mellgren A \& Parker S (2007) Does incontinence severity correlate with quality of life? Prospective analysis of 502 consecutive patients. Colorectal Disease 10, 273-279.

Brantelid I, Nivlér H \& Alehagen S (2013) Menstruation During a Lifespan: A Qualitative Study of Women's Experiences. Available at http://dx.doi.org/10.1080/07399332.2013.868465 (accessed 30 December 2013).

Brown S, Wadhawn H \& Nelson R (2013) Surgery for faecal incontinence in adults (Review) Avaliable at http://onlinelibrary.wiley.com/doi/10.1002/14651858.CD001757.pub4/pdf (accessed 1 January 2014).

Cooper J, Collier J, James V \& Hawkey C (2010). Beliefs about personal control and selfmanagement in 30-40 year olds living with Inflammatory Bowel Disease: A qualtitavtive study. International Journal of Nursing Studies 47, 1500-9.

Danielsen A, Soerensen E, Burcharth K \& Rosenberg, J (2013) Impact of a temporary stoma on patients' everyday lives: feelings of uncertainty while waiting for closure of the stoma. Journal of Clinical Nursing 22, 1343-1352.

Danielson J, Karlbom U, Sonesson A.-C, Wester T \& Graf W (2009) Submucosal Injection of Stabilized Nonanimal Hyaluronic Acid with Dextranomer: A New Treatment Option for Fecal Incontinence. Diseases of the Colon \& Rectum 52, 1101-1106. 
Danielson J, Karlbom U, Wester T \& Graf W (2013) Efficacy and quality of life 2 years after treatment for faecal incontinence with injectable bulking agents. Techniques in Coloproctology 17, 389-395.

Eastwood J, Moser D, Riegel B, Alber N, Pressler S, Chung M, Dunbar S, Wu J \& Lennie I (2012) Commonalities and differences in correlates of depressive symptoms in men and women with heart failure. European Journal of Cardiovascular Nursing 11, 356-65.

Heo S, Moser D \& Widener J (2007) Gender differences in the effects of physical and emotional symptoms on health-related quality of life in patients with heart failure. European Journal of Cardiovascular Nursing 6, 146-52.

Kvale S (1996) InterViews. 2nd edn. Sage Publications Ltd, London.

Lo J, Osterweil P, Li H, Mori T, Eden K \& Guise J-M (2010) Quality of Life in Women With Postpartum Anal Incontinence. Obstetrics and Gynecology 115, 809-814.

Lunniss P, Gladman M, Hetzer F, Williams N \& Scott M (2004) Risk factors in acquired faecal incontinence. Journal of the Royal Society of Medicine 97, 111-116.

Madoff R (2004) Surgical Treatment Options for Fecal Incontinence. Gastroenterology 126, S48-S54.

Manderson L (2005) Boundary breaches: the body, sex and sexuality after stoma surgery. Social Science \& Medicine 61, 405-415.

Melville J, Fan M-Y, Newton K \& Fenner D (2005) Fecal Incontinence in Us women: A population-based study. American Journal of Obstetrics and Gynecology 193, 2071-2076.

Mowatt G, Glazener C \& Jarret M (2009) Sacral nerve stimulation for faecal incontinence and constipation in adults (Review) Available at http://onlinelibrary.wiley.com/doi/10.1002/14651858.CD004464.pub2/pdf (accessed 1 January 2014).

Nelson R (2004) Epidemiology of Fecal Incontinence. Gastroenterology 126, S3-S7.

Norton N (2004). The Perspective of the Patient. Gastroenterology 126, S175-179.

Norton C, Burch J \& Kamm M (2005b) Patients' Views of a Colostomy for Fecal Incontinence. Diseases of the Colon \& Rectum 48, 1062-1069.

Norton C, Gibbs A \& Kamm M (2005a) Randomized, Controlled Trial of Anal Electrical Stimulation for Fecal Incontinence. Diseases of the Colon \& Rectum 49, 190-96.

Peden-McAlpine C, Bliss D \& Hill J (2008) The Experience of Community-Living Women Managing Fecal Incontinence. Western Journal of Nursing Research 30, 817-835.

Peden-McAlpine C, Bliss D, Becker B \& Sherman S (2012) The Experience of CommunityLiving Men Managing Fecal Incontinence. Rehabilitation Nursing 37, 298-306. 
Perry S, Shaw C, McGrother C, Matthews R, Assassa R, Dallosso H, Williams K, Brittain K, Azam U, Clarke M, Jagger C, Mayne C \& Castleden C (2002) Prevalence of faecal incontinence in adults aged 40 years or more living in the community. Gut: the journal of the British society of gastroenterology 50, 480-484.

Philip B \& Miner J (2004) Economic and Personal Impact of Fecal and Urinary Incontinence. Gastroenterology 126, S8-S13.

Pud D (2011) Gender differences in predicting quality of life in cancer patients with pain. European Journal of Oncology Nursing 15, 486-91.

Ratto C, Parello A, Donisi L, Litta F, De Simone V, Spazzafumo L \& Giordano P (2011) Novel bulking agent for faecal incontinence. British Journal of Surgery 98, 1644-1652.

Rotegård A, Fagermoen M \& Ruland C (2012). Cancer Patients' Experiences of Their Personal Strengths Through Illness and Recovery. Cancer Nursing 35, E8-17.

Smith JA \& Osborn M (2008) Interpretative Phenomenological Analysis. In J. A. Smith, Qualitative Psychology - A practical guide to research methods. Sage Publications Ltd, London, pp. 53-80.

Smith JA, Flowers P \& Larkin M (2009) Interpretative Phenomenological Analysis Theory, Method and Research. 2nd edn. Sage Publications Ltd, London.

Smith T, Menees S, Xu X, Saad R, Chey W \& Fenner D (2012). Factors associated with quality of life among women with fecal incontinence. The International Urogynecological Association 24, 493-99.

Stojkovic S, Lim M, Burke D, Finan P \& Sagar P (2006) Intra-anal collagen injection for the treatment of faecal incontinence. British Journal of Surgery 93, 1514-1518.

Swedish Code of Statutes (2003) The Act Concerning the Ethical Review of Research Involving Humans (SFS 2003:460). Available at http://www.epn.se/start/startpage.aspx (accessed 5 March 2013).

Tan E, Cornish V, Dorzi, A \& Tekkis P (2007) Surgical strategies for faecal incontinence - a decision analysis between dynamic gracioloplasty, artificial bowel sphincter and end stoma. Colorectal Disease 10, 577-86.

Tuteja A \& Rao S (2004) Recent trends in diagnosis and treatment of faecal incontinence. Alimentary Pharmacology \& Therapeutics 91, 829-840.

Walter S, Hallböök O, Gotthard R, Bergmark M \& Sjödahl R (2002) A Population-based Study on Bowel Habits in a Swedish Community: Prevalence of Faecal Incontinence and Constipation. Scandinavian Journal of Gastroenterology 37, 911-916.

Whitehead W, Borrud L, Goode P, Meikle S, Mueller E, Tuteja A, Weidner A, Weinstein M \& Ye W (2009) Fecal Incontinence in Us Adults: Epdiemologogy and Risk Factors.

Gastroenterology 137, 512-517. 
World Medical Association (2008) Medical Association Declaration of Helsinki- Ethical Principles For Medical Research Involving Human Patients. Available at http://www.wma.net/en/30publications/10policies/b3/index.html (accessed 4 March 2013). 